\title{
O DIREITO REAL DE KANT
}

Aylton Barbieri Durão ${ }^{1}$

RESUMO: No direito real, Kant investiga a propriedade privada de uma substância (o solo e os objetos localizados nele). No estado de natureza, somente ocorre a posse física ou empírica de um objeto externo, a partir do postulado jurídico da razão prática como uma lei permissiva, pois, do contrário, as coisas utilizáveis seriam em-si ou res nullius, mas a posse jurídica ou inteligível depende da posse comum originária do solo (que não se confunde com o comunismo primitivo), para evitar que a propriedade seja uma relação entre pessoas e coisas, como acontece na teoria do trabalho, porque todo direito exige um dever correspondente. Todavia, coisas não podem ter deveres com relação a pessoas, condição seguida da vontade unilateral do primeiro ocupante de querer o objeto e do advento de uma vontade unificada a priori do provo, que só se torna efetiva no estado civil, a única capaz de gerar uma obrigação recíproca entre todos; por isso, a posse inteligível somente é possível no estado civil, embora a posse empírica do estado de natureza tenha a presunção de tornar-se jurídica, quando ocorrer a entrada no estado jurídico e vale por comparação na espera e preparação daquele estado.

PALAVRAS-CHAVE: Kant. Direito. Propriedade. Trabalho. Vontade.

Segundo a definição metafórica apresentada por Kant sobre a arquitetônica da razão, o edifício da razão prática deve ser erguido em dois momentos: inicialmente, devem ser lançados os alicerces na parte crítica (Fundamentação da metafísica dos costumes e Crítica da razão prática) e, posteriormente, deve ser erguida a parte doutrinária (Metafísica dos costumes), na qual são expostos os princípios metafísicos das partes da razão prática.

${ }^{1}$ Professor Doutor da Universidade Federal de Santa Catarina. E-mail: Barbieri@cfh.ufsc.br 
A Metafísica dos costumes, por sua vez, é exposta segundo a ideia regulativa de que a humanidade se aproxima gradativamente dos princípios da razão prática, sem, contudo, jamais alcançá-los, o que determina a sequência em que é apresentada a doutrina e, consequentemente, a sua divisão interna: a humanidade se aproximará da legalidade antes do que da moralidade, por isso, a doutrina do direito precede a doutrina da virtude, bem como o estado de natureza antecede o estado civil, de modo que a doutrina do direito se subdivide em doutrina do direito privado e doutrina do direito público.

A doutrina do direito privado, que constitui a parte mais original da Metafísica dos costumes, uma vez que a doutrina do direito público já havia sido antecipada nas obras de história filosófica dos anos 1780 e de filosofia política dos anos 1790, dividindo-se evidentemente também em capítulos, segundo a ordem da aproximação assintótica aos ditames da razão prática. Por isso, depois de uma breve introdução sobre a divisão da doutrina do direito privado, Kant apresenta o argumento que fundamenta a propriedade privada em três capítulos: o primeiro (§1-9), intitulado "O modo de ter algo exterior como seu", refere-se, obviamente, ao estado de natureza, no qual somente é possível a posse empírica e provisória dos objetos externos do arbítrio, em virtude do postulado jurídico da razão prática, o qual demonstra que o uso de objetos externos que estão fisicamente sob o meu poder também deve poder estar juridicamente, porque, do contrário, eles seriam coisas-em-si, sem dono (res nullius), já que esse postulado é compatível com o princípio do direito pelo qual o livre arbítrio de cada um pode se conciliar com o livre arbítrio de todos os demais, de acordo com uma lei universal da liberdade e, dessa forma, constitui, por um lado, um fato da razão, que possibilita uma ampliação da razão prático-jurídica e, por outro lado, uma lei permissiva, consequentemente, com vigência apenas no estado de natureza, porque tem por finalidade evitar uma injustiça ainda maior, pois a simples permanência nesse estado, onde somente existe a posse empírica, mas não a posse inteligível dos objetos de nosso arbítrio, já constitui uma injustiça, na medida em que priva o possuidor do direito à propriedade, mesmo que nenhuma ação violenta seja realmente perpetrada; por isso, permite ao sujeito obrigar a todos aqueles com quais mantém uma relação a entrar no estado civil $^{2}$, unicamente no qual é possível uma posse inteligível e peremptória ${ }^{3}$.

\footnotetext{
${ }^{2} \mathrm{Na}$ verdade, a posse jurídica somente se realiza plenamente com a entrada de todos os sujeitos em uma relação legal-pública, o que só ocorre completamente, quando o direito político de cada estado estiver ordenado a partir da constituição republicana e o direito das gentes, que regula a relação entre os estados, estiver orientado pela federação de estados e pelo direito cosmopolita.

${ }^{3}$ Para uma análise mais detalhada desse primeiro capítulo, consultar o artigo: DURÃO, 2006, p. 225-242. Embora sejam independentes, o artigo atual pode ser considerado uma continuação daquele.
} 
Consequentemente, esse primeiro capítulo representa igualmente a primeira parte da fundamentação da posse jurídica, mas, embora a segunda e mais importante parte do argumento já é antecipada no §6, ela somente é desenvolvida no segundo capítulo "O modo de adquirir algo exterior como seu" (§10-35), que, depois de uma introdução no §10, é dividido em três seções: "O direito real" (§11-17), "O direito pessoal (§18-21) e "O direito pessoal de caráter real" (§22-30).

Essa segunda parte do argumento, na verdade, já começa nos dois últimos parágrafos do primeiro capítulo, porque eles representam uma transição ao segundo capítulo ${ }^{4}$. Kant pretende retomar uma versão da teoria consensual da propriedade, que foi desenvolvida, no começo da Modernidade, por Grocio e Pufendorf, modificando-a de tal modo que pudesse resistir às críticas de Locke, o qual a ridicularizou, a partir da alegação de que os indivíduos morreriam muito antes, caso tivessem que esperar o consentimento do contrato social para usufruir dos objetos da natureza; por isso, fundamentou a propriedade dos objetos externos pela propriedade que o indivíduo tem sobre seu próprio corpo, uma vez que nosso corpo tem a capacidade de transformar os objetos externos que se encontram inicialmente em estado de natureza e, portanto, não pertencem a ninguém, mediante o trabalho, acrescentado-lhes, consequentemente, o seu trabalho realizado sobre esse objeto, algo que pertence exclusivamente a esse primeiro trabalhador e cuja apropriação por outro homem representaria uma usurpação do trabalho alheio ${ }^{5}$. Locke, entretanto, considera que deve haver uma limitação na extensão da propriedade, pois um indivíduo só pode se apropriar dos objetos externos, se não for desperdiçá-los, mas com o desenvolvimento da civilização e do comércio, surgiu o dinheiro para facilitar o intercâmbio das mercadorias, constituído pelas moedas compostas de metal nobre, o ouro e a prata, cuja acumulação não pode causar desperdício. Também Rousseau, depois de condenar a propriedade como um roubo, no Discurso sobre a desigualdade, recusou que a propriedade pudesse ser fundamentada na mera exibição de sinais exteriores, como fincar uma bandeira na terra, aceitando a teoria do trabalho, em $O$ contrato social, embora a tenha modificado, distinguindo a posse do estado de natureza e a propriedade do estado civil e estabelecendo um limite para a propriedade, porque o indivíduo não pode possuir além de suas necessidades.

${ }^{4}$ Em A Metafísica dos costumes, existem muitos parágrafos de transição de uma parte anterior para uma posterior. A explicação para isso se deve a que esses parágrafos de transição remetem ao caráter temporal presente na própria razão prática, como se aludiu anteriormente, o qual é originado pela especificidade de que a razão prática é orientada pela ideia regulativa de que devemos nos aproximar constantemente de sua realização, sem jamais alcançá-la plenamente.

${ }^{5}$ LOCKE, John. Two Treatises of Government, §27 e 28, p. 287-9. 
A dedução kantiana da posse jurídica retoma a teoria do consentimento através do contrato originário, também ridicularizando a teoria do trabalho de Locke. O argumento consiste em mostrar que a posse jurídica constitui uma relação entre pessoas e não uma relação entre pessoas e coisas, como a teoria do trabalho leva a pensar; por conseguinte, a posse física dos objetos externos do arbítrio facultado pela liberdade externa exige, como pressuposto, a posse comum originária do solo, a posse física do objeto externo, acompanhada da decisão da vontade unilateral de possuí-lo, a qual não pode gerar a obrigação de abstenção por parte dos demais, algo que somente pode ocorrer mediante a vontade unificada de todos, que garante a posse jurídica e peremptória dos objetos externos do arbítrio.

\begin{abstract}
É por si mesmo tão claro que o primeiro trabalho, a delimitação ou, em geral, a conformação de um terreno não pode proporcionar título algum de aquisição do mesmo... que é difícil atribuir a outra causa aquela opinião dominante, tão velha e tão estendida, mais do que ao engano imperante de personificar as coisas e de imaginar imediatamente um direito frente a elas, como se alguém pudesse obrigá-las, mediante o trabalho aplicado nelas, a não estar à serviço de mais ninguém além do seu $[\ldots]^{6}$
\end{abstract}

Em consequência, a dedução do direito real começa a ser preparada já nos $\S 8$ e $\S 9$ do primeiro capítulo, os quais afirmam ser possível ter algo exterior como seu, apenas em um estado civil. A posse inteligível somente pode acontecer no estado jurídico, porque nele é instituída uma legislação legal-pública e uma justiça distributiva capazes de garantir para cada um o que é seu por direito, com a ajuda da coerção. Toda posse começa por minha declaração de que uma coisa é minha, porque quero que seja minha e, portanto, todos os demais estão obrigados a se abster de usar esse objeto de meu arbítrio. Sem que eu realize esse ato jurídico, não haveria nenhuma obrigação por parte dos outros de se absterem de usar um objeto do meu arbítrio; porém, a mera declaração de minha vontade apenas afirma o meu querer, sem o qual não pode existir a obrigação da parte de ninguém, visto que, unicamente se eu digo que quero que um objeto exterior de meu arbítrio seja meu, os outros têm a oportunidade de se sentirem obrigados a respeitar a minha vontade. Todavia, o ato jurídico de minha vontade unilateral exige uma atitude recíproca de todos os demais, pois uma obrigação não pode surgir simplesmente porque eu a quero. A reciprocidade demanda que o outro respeite o ato da minha vontade, sempre que eu respeite também a

${ }^{6}$ KANT, Immanuel. Die Metaphysik der Sitten. IKW VII, §17. p. 72-73. As palavras que foram sublinhadas, nesta citação, bem como nas subsequentes, aparecem em itálico no original. 
manifestação da sua vontade unilateral de declarar que um objeto exterior do seu arbítrio é o seu exterior e que os demais devem se abster de usá-lo. Se a posse resultasse exclusivamente da vontade unilateral, que é contingente e não pode servir de lei coativa para todos, isso prejudicaria a liberdade exterior do outro, porque o impediria de usar um objeto utilizável. Nesse sentido, a obrigação recíproca somente pode surgir da vontade unificada de todos, que é a única que pode ser imposta a todos e confirmar o seu exterior de alguém. Contudo, essa vontade coletiva, universal e comum só se torna efetiva com a legislação pública do estado civil ${ }^{7}$.

Não obstante, ao começar o §9, Kant parece mudar o rumo de sua argumentação e voltar à tese de que existem direitos naturais, no estado de natureza, os quais são apenas confirmados pela constituição civil do estado jurídico. Ele distingue dois tipos de leis presentes na constituição civil: as leis naturais, deduzidas de princípios a priori, e as leis estatutárias, provenientes do poder discricionário do legislador. Em seguida, afirma que as leis estatutárias não podem contrariar o direito natural. Isso implica que as relações de propriedade estabelecidas no estado de natureza, por meio do postulado jurídico da razão prática, têm validade também no estado civil, pois aquele que age de acordo com a máxima da ação que me impede de ter como meu um objeto externo do meu arbítrio afronta a minha liberdade externa; como consequência, a legislação pública tão só assegura os direitos de propriedade, sem poder modificar a situação herdada do estado de natureza. Por fim, como os direitos de propriedade já estão fixados no estado de natureza antes da constituição civil, para assegurar tais direitos, é lícito obrigar a qualquer um com quem nos relacionamos a entrar conosco no estado civil $^{8}$. Desse modo, o próprio estado civil parece resultar da necessidade de positivar os direitos naturais de propriedade.

Contudo, essa aparente contradição entre os $\S 8$ e 9 se resolve tão logo se compreende corretamente o argumento de Kant sobre a relação entre a posse no estado de natureza e no estado civil. No estado de natureza, existe apenas uma posse empírica, a qual é provisória, mas não uma posse inteligível, que é definitiva, porque a posse inteligível somente é possível pela instituição de uma justiça legal-pública, através da vontade unificada do povo, contudo, embora esta vontade comum não exista no estado de natureza, o possuidor dessa posse empírica provisória, que ocorre no estado de natureza, tem a presunção de que ela se tornará jurídica e definitiva com a instituição da vontade unificada do povo, no estado civil; trata-se, por conseguinte, de um direito que não é adquirido previamente, mas que o titular tem a expectativa de que se realizará, no futuro.

${ }^{7}$ Ibid., §8. p. 58-9

${ }^{8}$ Ibid., §9. p. 59. 


\begin{abstract}
Uma posse, que ocorre durante a espera e a preparação daquele estado, é uma posse jurídica provisória, porque esta pode ser fundamentada unicamente em uma lei da vontade comum e que concorda com a possibilidade desta última, enquanto a que se encontra em um estado real é uma posse peremptória... com outras palavras: o modo de ter algo exterior como seu no estado de natureza é a posse física, que tem para si a presunção jurídica de poder ser convertida em jurídica ao se unir com a vontade de todos em uma legislação pública, e vale, durante esta espera, como jurídica por comparação ${ }^{9}$.
\end{abstract}

Consequentemente, a posse empírica dos objetos externos no estado de natureza, autorizada pelo postulado jurídico da razão prática, a qual é uma lei permissiva que somente tem validade no próprio estado de natureza, possui uma validade jurídica, enquanto se espera e se prepara o estado civil, por comparação com a posse inteligível fundamentada pela vontade unificada do povo, visto que ela tem a presunção jurídica de se converter em jurídica, com a entrada efetiva no estado civil e, justamente por isso, a legislação pública apenas pode positivar os direitos naturais à posse empírica, sem modificá-los, transformando-a na posse inteligível.

Entretanto, a posse empírica não pode se converter em posse inteligível, caso não se realize a entrada no estado civil, dado que o postulado jurídico não garante a propriedade, mas simplesmente evita uma injustiça maior, a de permanecer em um estado não-jurídico, no qual ninguém tem garantido o direito ao meu e ao teu exterior, se a lei jurídica de uma justiça legal-pública não se tornar efetiva. Dessa interpretação podem-se extrair duas conclusões: (1) a legitimidade da posse de um objeto do arbítrio me autoriza a fazer renunciar a toda pretensão de usar um objeto de meu arbítrio àquele com quem mantenho uma convivência inevitável, no estado de natureza, mas que não quer entrar comigo no estado civil ou estado de liberdade legal pública, porque a própria coisa seria anulada em sentido prático, conforme o postulado da razão prática, com esse ato de sua parte, uma vez que as tornaria coisas-em-si ou res nullius, não tendo também

\footnotetext{
${ }^{9}$ Ibid., §9. p. 59-60. Atualmente, o Ordenamento Jurídico Brasileiro, bem como de vários países do mundo, possui institutos jurídicos semelhantes, inclusive para outros ramos do direito que se denomina expectativa de direito. A expectativa do direito consiste na possibilidade da aquisição de um direito, no futuro. Um exemplo ilustrativo da expectativa de direito ocorre na legislação sobre a aposentadoria: o direito à aposentadoria só é adquirido pelo trabalhador, quando ele integraliza o tempo de contribuição e a idade previstos na lei; antes desse fato, que ocorrerá no futuro, ele tem uma expectativa de direitos que lhe autoriza algumas reivindicações, mas que pode ser alterada a qualquer momento por outra legislação a respeito; somente quando o direito é adquirido, depois de cumpridas as exigências legais, é que a mudança da legislação não pode mais afetá-lo.
} 
nenhum direito a elas; portanto, sua posse somente está juridicamente determinada, se cumpre a obrigação de entrar no estado civil, do contrário, é um dever para qualquer pessoa fazê-lo renunciar a ela ${ }^{10}$; (2) como a passagem da posse física ou empírica, que é provisória e apenas tem validade comparativa na espera e preparação do estado civil, para a posse jurídica ou inteligível, a única que é definitiva, só se concretiza mediante a sua fundamentação pela vontade unificada do povo, a qual se tornará efetiva no futuro, nós também estamos autorizados a obrigar àqueles com quem mantemos relação a entrar no estado civil, com o propósito de garantir o direito ao meu e ao seu exterior de cada um. Nesse sentido, constitui-se na causa racional do estado civil, expressa no postulado do direito público segundo o qual é um dever obrigar a todos aqueles com os quais estamos em uma situação de convivência inevitável a sair do estado de natureza e entrar em um estado jurídico ${ }^{11}$.

Dessa maneira, a prova do direito de propriedade remete inevitavelmente ao capítulo 2, que é o núcleo da teoria do direito privado, dedicado a explicar como a vontade unificada do povo permite à vontade unilateral, fundada na posse comum originária do solo, adquirir algo exterior como seu.

Kant divide o segundo capítulo em três secções, baseando-se nas três categorias da relação demonstradas anteriormente, na Crítica da razão pura - substância, causalidade e comunidade ${ }^{12}$ - e conclui que existem três possibilidades de ter algo exterior como seu. Pode-se ter um direito real a uma coisa corporal, uma substância; um direito pessoal sobre o arbítrio de outro, podendo-se exercer sobre ele uma causalidade segundo a lei da liberdade exterior; e um direito pessoal de caráter real sobre um objeto exterior, como se ele fosse uma coisa, mas usá-lo como uma pessoa, pois os membros da sociedade formam uma comunidade, cujo núcleo é representado pela família, na qual se incluem também os empregados domésticos. Não obstante, a primeira seção, que investiga o direito real, representa a parte mais significativa de todo o argumento de Kant sobre a fundamentação da propriedade privada.

$\mathrm{Na}$ seção referente ao direito real, Kant pretende mostrar que a possibilidade de uma posse meramente inteligível depende do esclarecimento da definição de direito real como um direito entre pessoas, a qual pode ser facilmente mal interpretada como o direito das pessoas com

\footnotetext{
${ }^{10}$ Ibid., §9. p. 60.

${ }^{11}$ Ibid., §42. p. 113-4.

${ }^{12}$ Ibid., p. 63
} 
relação a coisas. O argumento de Kant para a solução da possibilidade da posse jurídica procede através de três passos: em primeiro lugar, a partir da definição do direito real como um direito entre pessoas, é possível demonstrar o erro das teorias da propriedade da ocupação e do trabalho, visto que estas confundem o direito real com um direito sobre coisas; em segundo lugar, a definição do direito real como um direito entre pessoas obriga a pressupor uma posse comum originária do solo como um fato da razão, porém, não como um fato histórico (comunismo primitivo), pois, sem a posse comum originária enquanto uma relação entre meu arbítrio com o arbítrio dos demais, a posse empírica do solo pelo primeiro ocupante teria que ser compreendida como uma relação entre seu arbítrio particular e a coisa, todavia, a posse comum originária permite mostrar que a primeira ocupação consiste em uma relação do arbítrio particular com o arbítrio dos demais, que lhe autoriza impedir qualquer outro de usar uma parte do solo. Por último, essa pretensão do arbítrio particular de possuir juridicamente o solo gera em todos os demais a obrigação de se abster de usar o objeto do meu arbítrio, contudo, como essa obrigação não pode resultar da simples vontade unilateral de um indivíduo, demanda inevitavelmente a vontade unificada do povo.

Kant começa o argumento que demonstra a possibilidade da posse meramente jurídica com a definição nominal de direito real como "o direito frente a todo possuidor de uma coisa", quer dizer, o direito real é o que possibilita que eu possa exigir de outro, que detém a coisa sem a minha autorização, que devolva a sua posse para mim. Essa definição, no entanto, pode deixar margem a dúvidas, uma vez que o direito de uma parte corresponde ao dever da outra, o que parece implicar uma obrigação da coisa exterior com relação ao seu possuidor. Kant comprova que o direito real não é uma relação entre pessoas e coisas, desenvolvendo um argumento que mostra que essa concepção conduziria a um absurdo. Se o direito real é o direito de uma pessoa sobre uma coisa, e todo direito tem como contrapartida um dever correspondente da outra parte, decorre que a coisa teria um dever com relação ao seu possuidor, o que só é possível se a coisa está tão ligada ao seu possuidor que leva uma espécie de marca do seu possuidor, de tal modo que não pode ser de mais ninguém e tem que ser restituída ao seu dono, tão logo seja alienada, pois tem uma obrigação para com ele. Essa interpretação conduz ao absurdo de personalizar a própria coisa, porque o direito do possuidor aparece como um "gênio" que acompanha eternamente a coisa e que a faz resistir a qualquer outro possuidor ${ }^{13}$.

A argumentação de Kant recorda muito a crítica posterior de Marx ao fetichismo das mercadorias que a economia política vulgar comete. Marx

\footnotetext{
${ }^{13}$ Ibid., § 11. p. 64
} 
distingue a economia política clássica, desenvolvida por Adam Smith e David Ricardo, enquanto verdadeira ciência, porque desenvolve corretamente os conceitos econômicos, da economia política vulgar, como simples ideologia burguesa. Para a economia política clássica, o trabalho, como uma relação social entre homens, determina o valor-de-troca das mercadorias, constituindo uma relação entre pessoas. A economia vulgar, por outro lado, considera que o valor-de-troca é um atributo inerente às coisas-em-si mesmas, como se fosse uma propriedade física ou química da própria mercadoria e, portanto, coisifica uma relação entre homens, dotando as mercadorias de qualidades sociais, como se tivessem uma alma humana. A economia vulgar mascara o papel do trabalho como relação social entre homens, na constituição das mercadorias, o que permite ocultar a apropriação da mais-valia e, consequentemente, a exploração do trabalhador ${ }^{14}$.

A comparação entre a personificação das coisas de Kant e o fetichismo das mercadorias de Marx se torna mais evidente, quando se recorda que Kant afirma que, se um homem estivesse totalmente sozinho sobre a terra, não poderia ter nenhuma coisa exterior como sua, porque entre ele e todas as demais coisas não pode haver nenhuma obrigação ${ }^{15}$.

Também Marx comenta como Robinson Crusoé, em sua ilha deserta, faz o inventário dos produtos do seu trabalho e lhes atribui um valor-detroca. Marx observa, contudo, que não é possível que os objetos do trabalho de Robinson Crusoé tenham valor-de-troca, porque o valor-de-troca é uma relação social proveniente do trabalho realizado em comum e não uma qualidade física ou química oculta nas mercadorias. A crítica marxista das "robinsonadas" específicas da ideologia burguesa ilustra o caráter social da produção de mercadorias ${ }^{16}$. A crítica kantiana sobre a personificação das coisas, por outro lado, tem a finalidade de evitar o erro daquela teoria que, em sua opinião, é a teoria dominante, "tão velha e tão estendida", de que se adquire uma coisa por meio do trabalho, estabelecendo um direito imediato sobre as coisas, como se alguém pudesse obrigar uma coisa a não estar ao serviço de mais ninguém, exceto ao seu ${ }^{17}$.

Para evitar a personificação do direito, Kant propõe a definição real do direito real, que afirma que o direito a um objeto exterior do arbítrio é o direito ao uso privado de uma coisa da qual se está na posse comum com todos os demais. Esse conceito de posse comum originária do solo propicia

\footnotetext{
${ }^{14}$ MARX, Karl. O capital. Livro I. p. 81.

${ }^{15}$ KANT, Immanuel. Die Metaphysik der Sitten. IKW VII, § 11. p. 64.

${ }^{16}$ MARX, Karl. O capital. Livro I. p. 85.

${ }^{17}$ KANT, Immanuel. Die Metaphysik der Sitten. IKW VII, § 17. p. 72-73.
} 
que se evite compreender o direito como uma relação direta entre as pessoas e as coisas, uma vez que a posse comum originária estabelece que a relação originária entre os arbítrios consiste na posse comum das coisas externas, as quais, segundo a liberdade externa, não podem existir como res nullius ${ }^{18}$. A posse comum originária só pode ser um fato da razão, portanto, um produto da liberdade que possibilita que a razão se amplie a si mesma, na medida em que coloca a todos os homens na situação de possuir em comum todos os objetos externos de seu arbítrio. Como uma determinação da razão, a posse comum originária é uma relação entre meu arbítrio e o arbítrio dos demais, quer dizer, uma relação entre pessoas para usar as coisas e não uma relação entre meu arbítrio e uma coisa. Por isso, a posse comum originária não é um conceito empírico que depende de condições temporais, mas uma condição de possibilidade, cujo caráter transcendental é necessário para que toda posse empírica posterior estabeleça uma relação entre as liberdades de arbítrio, por conseguinte, entre pessoas e nunca entre as pessoas e as coisas ${ }^{19}$.

Por esse motivo, a posse comum originária não pode ser confundida com a posse comum primitiva ou comunidade primitiva, que é um conceito inventado, embora jamais demonstrado, de um suposto fato histórico, segundo o qual os primeiros homens viviam em sociedades baseadas na propriedade comunal do solo. Entretanto, se a posse comum originária fosse o conceito empírico de uma comunidade de propriedade, teria ocorrido uma relação entre homens e coisas, da qual seria derivado o direito à propriedade, com a única diferença de que, em lugar de uma apropriação individual do solo, neste caso, aconteceria uma apropriação coletiva, por meio da qual todos, em conjunto, teriam se apoderado diretamente dos objetos externos, de sorte que, ao distinguir rigorosamente a posse comum originária do comunismo primitivo, Kant nega que este último seja originário, mas, ainda que negue igualmente que o comunismo possa ser primitivo, afirma claramente que ele pode ser derivado por meio de um contrato de renúncia à posse privada ${ }^{20}$.

Segundo Delbos, a posse comum originária explica por que a minha propriedade de uma coisa que está sob minha posse acarreta a obrigação de meus semelhantes terem que se abster de usá-las sem o meu consentimento e desistir de toda pretensão sobre ela, deixando-a para meu uso exclusivo. Na verdade, o ato de permissão para usar o objeto do meu arbítrio supõe um

\footnotetext{
${ }^{18}$ Ibid., § 11. p. 64

${ }^{19}$ Ibid., § 13. p. 66

${ }^{20}$ Ibid., § 6. p. 52-4.
} 
estado segundo o qual nenhum arbítrio seria excluído da posse de nenhum objeto, portanto, uma posse comum originária, já que a renúncia a possuir uma coisa pressupõe a posse de tal coisa, de maneira que é necessário considerar esse estado de propriedade em comum como um estado que teria originariamente existido, mas como uma ideia da razão prática e não como fato histórico. Assim, o direito de propriedade se funda sobre a relação do proprietário com outras pessoas, que inicialmente se encontravam idealmente investidas do mesmo direito de propriedade sobre os objetos ${ }^{21}$.

Contudo, a posse comum originária não é suficiente para explicar o direito de propriedade, porque ela somente demonstra que o direito a usar coisas externas é uma relação entre as pessoas e não diretamente uma relação entre pessoas e coisas; para que o arbítrio de cada um seja autorizado a se apropriar privadamente das coisas externas que são possuídas em comum, é necessária, além do mais, tanto a vontade unilateral do primeiro ocupante de possuir o objeto privadamente, quanto a vontade unificada do povo, pois o direito de propriedade implica uma obrigação entre as partes de se abster de usar os objetos externos do arbítrio dos outros, porque a vontade unilateral não pode gerar obrigação da parte dos demais. O dever de se abster de usar um objeto do arbítrio do outro depende do consentimento recíproco de que eu não use o objeto do arbítrio do outro, sempre que o outro aceite também, como um dever, não usar, sem a minha permissão, um objeto do meu arbítrio. Nesse sentido, unicamente o acordo expresso na vontade de todos, que é unificada a priori, pode resultar na autorização para o uso privado, pela vontade unilateral, de um objeto que esta queira ${ }^{22}$.

Do exposto se conclui que todos devem ter uma posse comum originária, que é uma relação entre os arbítrios livres, porque é um produto da razão que obriga igualmente a todos; sem essa determinação a priori da razão, qualquer posse empírica seria uma relação entre pessoas e coisas, mas, como isso é um absurdo, é preciso conceber uma posse comum originária como relação entre pessoas; contudo, essa posse comum não garante o meu uso privado do objeto exterior do meu arbítrio. Tampouco minha vontade unilateral pode garanti-lo. De fato, a relação entre as vontades unilaterais seria mais bem descrita como uma situação de disputa entre si, anulando qualquer pretensão privada ao uso dos objetos. Logo, a posse privada de um objeto exterior pela vontade unilateral tem que ser acompanhada pela obrigação da abstenção recíproca, o que somente pode resultar da vontade unificada que obriga a priori ${ }^{23}$. A combinação da posse

${ }^{21}$ DELBOS, V. La philosophie pratique de Kant. p. 564

${ }^{22}$ KANT, I. Die Metaphysik der Sitten. IKW VII. § 16. p. 70-71.

${ }^{23}$ DELBOS, V. La philosophie pratique de Kant. p. 565. 
comum inata (originária) do solo e a vontade universal permitem ao possuidor ter a posse inteligível privada de um objeto externo do seu arbítrio ${ }^{24}$.

Por conseguinte, partindo da combinação do que ele denomina o "título da aquisição", ou seja, ideia da comunidade originária do solo, que oferece as condições espaciais para a posse exterior, com o que ele chama de o "modo de aquisição", que pode ser encontrado nas condições empíricas da tomada de posse, associado com a vontade de ter o objeto exterior como seu, Kant apresenta analiticamente a dedução do conceito de aquisição originária, a partir do próprio conceito de posse inteligível, retirando do mesmo tudo o que provém da sensibilidade, o que significa que apenas permanece no conceito de posse inteligível a relação entre as vontades particulares e a vontade universal. O argumento kantiano consiste em mostrar que, como conceito prático-racional, o conceito jurídico do meu e do teu exterior somente pode subsumir conceitos puros do entendimento e deve abstrair de todas as intuições sensíveis dos objetos. No âmbito da razão teórica, os conceitos têm que subsumir intuições empíricas que, por sua vez, já resultam da síntese entre as intuições a priori do espaço e do tempo com as sensações; contudo, a razão prática, inclusive em sua função jurídica, tem que seguir o caminho inverso ao da razão teórica e, em lugar de subsumir intuições, elimina tudo o que provém da sensibilidade; desse modo, o meu e o teu exterior que se encontra "fora de mim" somente pode significar um objeto distinto de mim mesmo e não um objeto localizado em um espaço e tempo diferente daquele em que estou. Depois da abstração de todas as condições sensíveis relativas à posse empírica do objeto, só resta o simples conceito puro do entendimento de ter um objeto sob minha potestade. Porém, com a eliminação de todo o sensível, desaparece também qualquer relação da pessoa com os objetos que não têm obrigação jurídica para com ela, porque o conceito de posse inteligível é um produto da razão prático-jurídica que não guarda nada de sensível, visto que é unicamente uma determinação da razão. O que fica no conceito de posse inteligível é somente a relação de uma pessoa com as outras pessoas, quer dizer, a obrigação recíproca de usar os objetos do seu arbítrio e de se abster de usar o objeto do arbítrio alheio. Tal relação entre pessoas é uma relação entre a vontade particular e a vontade universal e, por conseguinte, o direito de propriedade, para Kant, se resume em uma autorização dada pela vontade universal para que a vontade particular se aproprie de um objeto do seu arbítrio. Ou seja, o direito de propriedade consiste no consentimento de todos de que cada um use um objeto privadamente; todavia, esse acordo não é resultado de uma negociação, mas uma imposição da razão prático-jurídica.

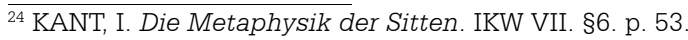




\begin{abstract}
Portanto, a eliminação ou omissão (abstração) das condições sensíveis da posse, como relação das pessoas com objetos que carecem de obrigação, não é senão a relação de pessoas com pessoas, que consiste em obrigar a todas elas, no que se refere ao uso das coisas, pela vontade da primeira, na medida em que ela coincide com o axioma da liberdade exterior, com o postulado da faculdade e da legislação universal da vontade pensada como unificada a priori, o que, portanto, é a posse inteligível das coisas, a posse pelo mero direito, embora o objeto (a coisa que possuo) seja um objeto sensível25.
\end{abstract}

O resultado de tal dedução é o princípio universal da aquisição de uma coisa exterior, mediante o qual Kant começa o segundo capítulo. O que, por minha vontade unilateral, submeto à minha potestade, na medida em que concorda com o axioma da liberdade exterior, posso usá-lo como objeto de meu arbítrio, conforme o postulado jurídico da razão prática, e o que eu quero que seja meu, com base na vontade unificada de todos, em decorrência, é meu. Portanto, os momentos da aquisição são a apreensão de um objeto que não pertence a ninguém, pois, do contrário, se ofenderia a liberdade de arbítrio de outros; a declaração da posse do objeto do meu arbítrio, no que se revela a minha vontade particular de tê-lo sob minha posse; e, por fim, a apropriação, que representa o consentimento de todos por meio da vontade universal ${ }^{26}$.

Consequentemente, da argumentação de Kant sobre o direito privado se revela a concordância entre a liberdade de arbítrio e a vontade universal ${ }^{27}$. $\mathrm{O}$ argumento de Kant começa por demonstrar que é conforme com a liberdade exterior que o livre arbítrio de cada um, no uso dos objetos exteriores do seu arbítrio, é compatível com o livre arbítrio de todos os demais, segundo uma lei universal, o que possibilita a posse empírica dos objetos utilizáveis, e termina por provar que a vontade unificada do povo, ao permitir o uso privado dos objetos externos pela vontade unilateral, garante a posse jurídica ou inteligível.

Porque o direito frente a qualquer possuidor de uma coisa somente significa a faculdade do arbítrio particular para usar um objeto, na medida em que pode ser pensada como contida na vontade sintéticouniversal e como estando de acordo com a sua lei ${ }^{28}$.

\footnotetext{
${ }^{25}$ Ibid., § 17. p. 72.

${ }^{26}$ Ibid., § 10. p. 61-2.

${ }^{27}$ Ibid., § 14. p. 67.

${ }^{28}$ Ibid., § 17. p. $72-3$.
} 
Por fim, Kant trata como último problema do direito real, nas passagens finais do §17, uma questão referente à limitação da extensão da propriedade privada. De forma tangencial, o tema das dimensões da propriedade já fora abordado anteriormente, no segundo capítulo, dedicado ao direito político, de Teoria e práxis, quando ele alude à igualdade como o segundo dos princípios a priori do estado civil, que define como a capacidade de qualquer cidadão do povo poder exercer uma coação sobre os demais, excluindo-se apenas a coação sobre o chefe do estado, de modo que a ação de um pode ser acompanhada pela reação do outro, a qual considera como compatível com máxima desigualdade material entre os indivíduos da sociedade. Essa afirmação pode ser apressadamente confundida como uma fundamentação da desigualdade, na posse da propriedade privada e até como uma defesa de ideais liberais, embora nem toda concepção liberal seja conciliável com a desigualdade material ou, pelo menos, com a máxima desigualdade material, como menciona Kant. No entanto, uma reflexão simples leva a compreender que a análise do principio a priori da igualdade exposta por Kant não constitui uma fundamentação explícita da desigualdade material, uma vez que ele somente sustenta que a igualdade de ação e reação entre os membros do povo é compatível com a máxima desigualdade material, o que quer dizer que é um princípio a priori do estado de direito garantir que, ainda que as pessoas possuam uma enorme desigualdade material, as instituições sejam organizadas de tal maneira que permitam, mesmo àqueles que estão nas condições menos favorecidas, reagir às ações dos mais poderosos, sejam estes indivíduos, organizações ou empresas. Portanto, o estado civil exige, como um princípio a priori, a igualdade formal de ação e reação entre os seus membros, mas não uma igualdade material ${ }^{29}$.

Embora Kant pudesse ser censurado pela ingenuidade de supor que é possível alcançar essa igualdade formal em condições de extrema desigualdade material, não se trata, entretanto, de uma fundamentação da desigualdade na posse da propriedade porque, para isso, Kant teria que estabelecer uma relação necessária entre elas, sendo que a única coisa que ele afirma é que a igualdade de ação e reação é compatível com a desigualdade material. Todavia, se não existe nenhuma dedução da desigualdade no trecho mencionado, pode-se afirmar que, em algum sentido, Kant a admite pelo simples fato de que ele não a recusa, como caberia esperar, caso ele considerasse que a razão prática determinasse uma limitação da propriedade. Por conseguinte, a passagem final do §17, na qual Kant indica explicitamente uma limitação da propriedade privada, parece estar em

\footnotetext{
${ }^{29}$ Id., Über den Gemeinspruch: das mag in der Theorie richtig sein, taugt aber nicht für die Praxis. IKW VI. p. 374-377.
} 
contradição com as afirmações anteriores sobre o princípio a priori da igualdade, em Teoria e práxis.

No entanto, uma análise dos argumentos do §17 demonstra que essa limitação sobre a propriedade privada refere-se a um caso muito específico e não pode ser extrapolada, em hipótese nenhuma, a ponto de se considerar que Kant apresenta uma teoria dos limites da extensão da propriedade, como o fizera, por exemplo, Rousseau, porque Kant está discutindo simplesmente a questão de se o direito de propriedade do solo pode ser estendido também para as águas que lhe são contíguas, como o mar ou os rios que rodeiam um terreno. Kant afirma taxativamente, embora não exponha explicitamente, que, dos princípios apresentados anteriormente, deriva que o fundo do mar somente pode ser a continuidade de um terreno até onde o proprietário puder defendêlo mecanicamente, a partir de sua residência, como ocorre com os países que só podem possuir águas territoriais até onde puderem defendê-las com seus canhões situados no litoral, limitação que não deve ocorrer no segundo caso, pois um indivíduo pode ser proprietário das duas margens de um rio.

Apesar de estar explícito que, no trecho mencionado, Kant somente pretenda demonstrar a limitação da posse inteligível quando o solo é contíguo ao mar, pode-se aduzir duas outras razões adicionais que o confirmam: em primeiro lugar, o problema é muito importante para que Kant o apresente, nas últimas passagens de seu estudo sobre o direito real e sem uma dedução formal; em segundo lugar, quando ele trata, nas outras duas seções, do direito pessoal, que rege as relações contratuais entre os indivíduos, e do direito pessoal de caráter real, que regula as relações entre os membros da sociedade doméstica, o marido, a mulher, os filhos e os empregados domésticos, não existe nenhuma consideração paralela sobre a limitação da propriedade, exceto, naturalmente, a determinação do casamento monogâmico, a qual não é exposta, contudo, como um caso de limitação da propriedade, mas como uma exigência da própria natureza da posse inteligível para esse caso, definida como a posse recíproca dos órgãos sexuais do casal de gêneros diferentes.

DURÃO, Aylton Barbieri. Kant's real right. Trans/Form/Ação, (Marília); v.33, n.2, p.77-94, 2010.

ABSTRACT: In real right, Kant investigates the private property of a substance (the soil and the objects on it). In the state of nature the physical or empirical possession of an external object only occurs based on the juridical postulate of the practical reason as a permissive law; otherwise, usable things would be in themselves, or res nullius, but the juridical or intelligible possession depends on the common possession which originates from the soil (and cannot be confounded with primitive 
communism), to avoid the property to be a relation among people and things, such as what happens in the work theory, because all rights demand a correlated duty, but things cannot have duties towards people, followed by the first occupant's unilateral will to want the object and the advent of an a priori unified will of the people, which only becomes effective in the civil state, the one that is able to generate a reciprocal obligation among all; that is why the intelligible possession is only possible in the civil state, even though the empirical possession of the state of nature has the presumption to become juridical when the entrance in the juridical state occurs and serves by comparison in the wait and preparation of that state.

KEYWORDS: Kant. Right. Property. Work. Will

\section{Referências}

BAYNES, Kenneth. The normative grounds of social criticism: Kant, Rawls and Habermas. Albany: SUNY, 1992.

BOBBIO, Norberto. Diritto e stato nel pensiero di Emanuele Kant. Torino: Giappichelli, 1965.

COLOMER MARTÍN-CALERO, José Luis. La teoría de la justicia de Immanuel Kant. Madrid: CEC, 1995.

DELBOS, Victor. La philosophie pratique de Kant. Paris: PUF, 1969.

DURÃO, Aylton. O postulado jurídico da razão prática como lei permissiva. In: FILOSOFIA KANTIANA DO DIREITO E DA POLÍTICA: SEMINÁRIO INTERNACIONAL. Lisboa: Centro de Filosofia da Universidade de Lisboa, 2006. p. 225-242.

FAGGION, Andrea. A dedução da possibilidade da posse jurídica na doutrina do direito de Kant. Kant e-Prints, Campinas, v. 3, n. 4, p. 1-18, 2004.

GREGOR, Mary. Kant's theory of property, Review of Metaphysics, Washington, v. 41, p. 57-87, jun. 1988.

HABERMAS, Jürgen. Faktizität und Geltung: Beitrage zur Diskurstheorie des Rechts und des demokratischen Rechtsstaats. Frankfurt am Main Suhrkamp Verlag, 1994.

Die Einbeziehung des Anderen: studien zur politischen theorie.

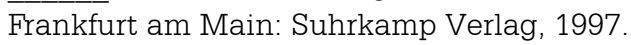

HECK, José N. Estado e propriedade na doutrina do direito de Kant. Veritas, Porto Alegre, v. 43, n. 1, p. 169-179, 1998.

HRUSCHKA, Joachim. The permissive law of practical reason in Kant's metaphysics of morals, , p. 45-72, Jan. 2004. 
KANT, Immanuel. Immanuel Kants Werke. Herausgegeben von Ernest Cassirer, Berlin: Bruno Cassirer, 1922. 11 v.

LOCKE, John. Two treatises of government. Cambridge: Cambridge University Press, 2008.

LOPARIC, Zeljko. O problema fundamental da semântica jurídica de Kant. In: WRIGLEY, Michael B.; SMITH, Plinio J. (Org.). O filósofo e sua história (uma homenagem a Oswaldo Porchart). Campinas: UNICAMP, CLE, 2003. p. 477-520.

MARX, Karl. O capital. Trad. Reginaldo Sant'Anna. Rio de Janeiro: Civilização Brasileira, 1980.

PHILONENKO, Alexis. Théorie et praxis dans la pensée morale et politique de Kant et de Fichte en 1793. Paris: J. Vrin, 1976.

RODRÍGUEZ ARAMAYO, Roberto. Crítica de la razón ucrónica. Madrid : Tecnos, 1992.

ROUSSEAU, Jean-Jacques. Du contrat social. In: Euvres complètes. Paris: Seuil, 1971. v. 2, p. 518-585.

Discours sur l'origine et les fondements de l'inégalité parmi les hommes. Paris: Gallimard, 2003.

SHELL, Susan. Kant's theory of property. Political Theory, Beverly Hills, v. 6, n. 1, p. 75-90, Feb. 1978.

TERRA, Ricardo. A doutrina kantiana da propriedade. Discurso, São Paulo, n. 14, p. 113-143, $1^{\circ}$ sem. 1983.

TIERNEY, Brian. Kant on property: the problem of permissive law. Journal of the History of Ideas, Philadelphia, v. 62, n. 2, p. 301-312, Apr. 2001.

VERHAEGH, Marcus. Kant and property rights, Journal of Libertarian Studies, New York, v. 18, n. 3, p. 11-32, summer 2004.

VLACHOS, Georges. La pensée politique de Kant. Paris: PUF, 1962.

WEINRIB, Ernest. The idea of private law. Cambridge Mass.: Harvard University Press, 1995.

WILLIAMS, Howard. Kant's concept of property. In: CHADWICK, Ruth F. (Ed.). Immanuel Kant: critical assessments. London; New York: Routledge, 1992, v. 3, p. 389-398. 